Bangladesh Journal of Neuroscience 2016; Vol. 32 (1): 16-20

\title{
Clinical Profile of Stroke Patients Attended in a Tertiary Care Hospital- Study of 219 cases
}

\author{
NAYEEM ANWAR ${ }^{1}$, MD. REZAUL KARIM KHAN ${ }^{2}$, NAWREEN BINTE ANWAR ${ }^{3}$ \\ SHAMSUN NAHAR ${ }^{4}$, MD. SHAHIDULLAH ${ }^{5}$
}

\begin{abstract}
:
Background: Stroke is serious pathology with a immense impact on the functional and vital prognosis. It is the leading cause of death worldwide. The objective of the study was to observe clinical profile of stroke patients and important risk factors. Methods: It was a cross-sectional descriptive study conducted in the department of Neurology, Bangabandhu Sheikh Mujib Medical Universiy(BSMMU), Shahbag, Dhaka from August 2014 to November 2015. All patients above 18 years of age and both sexes attending the above mentioned department meeting all inclusion and exclusion criterias and confirmed CT/MRI scan of Brain were included in this study. Results: A total of 219 patients were studied. Maximum 93(42.5\%) patients were in age group of $61-70$ years followed by $51(23.3 \%)$ and $30(13.7 \%)$, in the age group of 51-60 years and 71-80 years respectively. Male 138(63\%) were predominant than female $81(63 \%) .78(35.61 \%)$ patients had weakness in both sides of the body, 66(30.1\%) had weakness in the left side and 36(16.4\%) had weakness in the right side of the body. 190 (87.7) patients had ischemic stroke and 29(12.3\%) had hemorrhagic stroke. Among risk factors dyslipidemia was in 185(84.5\%) patients, hypertension, smoking habits, diabetes mellitus and ischemic heart disease were present in 165(75.3\%), 120(54.8\%), 105(47.9\%) and 42 (19.2\%) patients respectively. H/O recurrent stroke was present in 55(25\%) cases. Conclusion: Stroke cases were male predominant where dyslipidaemia was the most common risk factor, most common type of stroke was ischemic, most common presentation was hemiplegia/monoplegia and commonest age of presentation was seventh decade.
\end{abstract}

\section{Introduction:}

Stroke is a devastating and disabling cerebrovascular disease with significant amount of residual neurological deficit leading to great economic loss. It has been defined as a rapidly developing signs of focal (or global) disturbance of cerebral function with symptoms lasting for e"24hours or leading to death with no apparent cause other than vascular origin ${ }^{1}$. It is a collection of clinical syndromes resulting from cerebral ischemia or hemorrhage. In the west, it is the $3^{\text {rd }}$ most common cause of mortality and commonest cause of morbidity among the elderly persons ${ }^{2}$. Some of the recent studies have found that the stroke prevalence is of considerable extent in this subcontinent ${ }^{3}$. A recent study identified that $7 \%$ of medical and $45 \%$ of neurological admissions were due to stroke with a fatality rate of $9 \%$ at hospital discharge and $20 \%$ at 28 days $^{4}$. Dyslipidemia, hypertension, smoking and diabetes mellitus are the common causes of stroke among the elderly, ${ }^{5}$ and smoking, dyslipidemia, increased BMI, diabetes mellitus and hypertension are significantly associated with strokes among young people ${ }^{6}$. Ischemic strokes account for $50-80 \%$ of all strokes worldwide ${ }^{7}$. Heamorrhagic strokes are due to subarachonoid hemorrhage or intracerebral hemorrhage. They account for $1-7 \%$ and $7-27 \%$ respectively of all strokes worldwide ${ }^{8}$. Recently Bangladesh Baureu of statistics has estimated that

1. FCPS (Neurology) Final Part Student, Dept of Neurology, BSMMU, Dhaka.

2. Professor, Dept of Neurology, BSMMU, Dhaka.

3. Intern, Holy Family Red Cresent Medical College \& Hospital, Dhaka

4. Professor \& Chairman, Dept of Physical Medicine \& Rehabilitation, BSMMU, Dhaka.

5. Associate Professor, Dept of Neurology, BSMMU, Dhaka. 
the number of strokes has increased significantly and it occupies the number one position (16.4\%) of mortality among elderly persons, ischemic heart disease being the $2^{\text {nd }}(12.6 \%)$ and respiratory tract infection being the $3^{\text {rd }}(11.4 \%) .{ }^{8}$ The global burden of disease study also projects the similar findings worldwide by the year 2020. ${ }^{10}$ Hence this study was undertaken in our setup to study various aspects of stroke which will help young physicians to deal with this deadly and disabling disease.

\section{Meterials and methods:}

It was a cross-sectional descriptive study conducted in stroke clinic, In-patients and out-patients department of Department of Neurology, Bangabandhu Sheikh Mujib Medical University (BSMMU), Shahbag, Dhaka from August, 2014 to November, 2015. All patients above 18 years of age and both sexes attending the above mentioned department meeting all inclusion and exclusion criteria were included in this study. Total 219 consecutive patients were selected on the basis of history, clinical examination and findings of CT or MRI scan of Brain. The following information's were collected from each patient- age, sex, occupation, educational status, past history of stroke, hypertension, diabetes mellitus, coronary artery disease, family history of stroke, current or previous history of smoking, alcohol consumption, tobacco chewing, dietary history and others. Examination findings including hemiplegia/monoplegia, dysphasia/dysarthria, pulse, BP, carotid bruit, cardiac murmur etc were noted. Fasting serum lipid profile, blood sugar, S. Creatinine, S. electrolytes, ECG, eco-cardiogram, X-ray chest and relevant other investigations were done. Data analysis was done by using SPSS (statistical package for social science) soft ware version 18. Results were expressed in frequencies and percentages.

\section{Selection Criteria:}

Inclusion criteria: All patients clinically diagnosed as first or recurrent stroke (ischemic or hemorrhagic) confirmed by CT/MRI scan of Brain, age 18years or above and of both sexes.

Exclusion criteria: Patients less than 18years of age, advanced medical conditions (acute myocardial infarction, left ventricular failure, end stage renal disease, malignancy etc), metabolic and toxic states resembling stroke and patients unwilling to participate in the study.

\section{Results and observations:}

Table-I

Distribution of patients according to age (n-219).

\begin{tabular}{lcc}
\hline Age & Frequency & Percentage \\
\hline d"40 & 9 & 4.1 \\
$41-50$ & 21 & 9.6 \\
$51-60$ & 51 & 23.3 \\
$61-70$ & 93 & 42.5 \\
$71-80$ & 30 & 13.7 \\
$>80$ & 15 & 6.3 \\
\hline Total & 219 & 100.00 \\
\hline
\end{tabular}

Table-: I. Shows most of the Patients were above 50 years of age. Maximum 93(42.5\%) patients were in the age group of 61-70 years, followed by $51(23.3 \%)$ and $30(13.7 \%)$ in the age group of 51 $60 y e a r s$ and 71-80years respectively.

Table-II

Distribution of Patients according to gender (n-219).

\begin{tabular}{lcc}
\hline Gender & Frequency & Percentage \\
\hline Male & 138 & 63.0 \\
Female & 81 & 37.0 \\
\hline Total & 219 & 100.0 \\
\hline
\end{tabular}

Table-II: Shows distribution of patients according to gender. Male 138(63\%) were predominant than female $81(37 \%)$. Male female ration was 1.7:1

Table-III

Distribution of patients according to educational status (n-219)

\begin{tabular}{lcc}
\hline Education & Frequency & Percentage \\
\hline Illiterate & 27 & 12.3 \\
Primary & 66 & 30.1 \\
Secondary & 63 & 28.8 \\
Higher Secondary & 42 & 19.2 \\
Graduate \& above & 21 & 9.6 \\
\hline Total & 219 & 100.0 \\
\hline
\end{tabular}


Table-III Shows distribution of patients according to educational status. Maximum 66(30.1\%) patients completed their primary education followed by $63(28.8 \%)$ and $42(19.2 \%)$ patients completed their secondary and higher secondary education respectively.

Table-IV

Distribution of patients according to occupation (n-219)

\begin{tabular}{lcc}
\hline Occupation & Frequency & Percentage \\
\hline Housewife & 48 & 21.9 \\
Service holder & 39 & 17.8 \\
Business & 12 & 5.5 \\
Others & 120 & 54.8 \\
\hline Total & 219 & 100.0 \\
\hline
\end{tabular}

Table-: IV. Shows distribution of patients according to their occupation. Forty eight (21.9) patients were house-wife, 39(17.8\%) were service holder and 120(54.8\%) patients had miscellaneous occupation.

Table-V

Distribution of patients according to weakness of part of the body (hemiplegial monoplagia) (n-219).

\begin{tabular}{lcc}
\hline $\begin{array}{l}\text { Hemiplegia/ } \\
\text { monoplagia }\end{array}$ & Frequency & Percentage \\
\hline Right & 36 & 16.40 \\
Left & 66 & 30.13 \\
Bilateral & 78 & 35.61 \\
No & 39 & 17.8 \\
\hline Total & 219 & 100.00 \\
\hline
\end{tabular}

Table-V. Shows distribution of patients according to hemiplegia/monoplegia. Among them 78(35.61) patients had bilateral hemiplegia, 66(30.13\%) had left sided and $36(16.40 \%)$ patients had right sided hemiplegia.
Table-VI

Distribution of patients according to type of stroke (n-219)

\begin{tabular}{lcc}
\hline Stroke type & Frequency & Percentage \\
\hline Ischemic & 190 & 87.7 \\
Hemorrhagic & 29 & 12.3 \\
Total & 219 & 100.0 \\
\hline
\end{tabular}

Table-: VI. Shows distribution of patients according to type of stroke. 190(87.7\%) patients had ischemic and 29(12.3\%) patients had hemorrhagic stroke.

Table-VII

Distribution of patients according to risk factors $(n-219)$

\begin{tabular}{lcc}
\hline Risk factors & Frequency & Percentage \\
\hline Dyslipidemia & 185 & 84.5 \\
Hypertension & 165 & 75.3 \\
Smoking habit & 120 & 54.8 \\
Diabetes mellitus & 105 & 47.95 \\
P/H/O stroke & 55 & 25.1 \\
Ischemic heart disease & 42 & 19.2 \\
Alcohol & 12 & 5.5 \\
Rheumatic Heart disease & 03 & 1.4 \\
\hline
\end{tabular}

Table-: VII. Shows distribution patients according to risk factors. Here dyslipidemia (84.5\%), hypertension (75.3\%), smoking habit (54.8\%) and diabetes mellitus (47.95\%) were the common risk factors.

\section{Table-VIII}

Distribution of patients according to clinical presentation $(n-219)$

\begin{tabular}{lcc}
\hline Clinical Features & Frequency & Percentage \\
\hline Altered sensorium & 31 & 14.15 \\
Instability of gait & 15 & 6.85 \\
Convulsions & 18 & 8.22 \\
Speech involvement & 62 & 28.31 \\
Headache & 05 & 2.28 \\
Vomiting & 25 & 11.41 \\
Hemiplegia/monoplegia & 180 & 82.19 \\
\hline
\end{tabular}


Table-VIII Shows distribution of patients according to clinical presentation. Hemiplegia/monoplagia 180 (82.19\%), speech involvement 62(28.31\%) and altered sensorium $31(14.15 \%)$ were the common presentations.

\section{Table-IX}

Gender wise distribution of different types of stroke (n-219)

\begin{tabular}{lccc}
\hline Gender & Ischemic & Hemorrhagic & Total \\
\hline Female & $70(32 \%)$ & $11(5 \%)$ & $81(27.00)$ \\
Male & $120(54.8 \%)$ & $18(8.2 \%)$ & $138(63.0)$ \\
\hline Total & $190(86.77 \%)$ & $29(13.3)$ & $219(100)$ \\
\hline
\end{tabular}

Table-: IX. Shows gender wise distribution of patients according to different types of stroke. Here among 190(86.77\%) ischemic stroke patients $120(54.8 \%)$ were male and $70(32 \%)$ were female. And among 29(13.3\%) hemorrhagic stroke $29(13.3 \%)$ patients $18(8.2 \%)$ were male and $11(5 \%)$ were female. So, in both types of stroke male is predominant than female.

\section{Discussion:}

In this study it was observed that mean age of stroke patients was $67.5 \pm 42.5$ years which correlates with study done by Chirayu et al(mean age 64years) ${ }^{9}$, Maskay et al (mean age 63 years) ${ }^{11}$ and Awad et al(mean age 63.66years) ${ }^{12}$. The common age group was in between 61-70years (42.5\%) which correlated with the studies done by Upoha et al ${ }^{13}$, and Maskey et $\mathrm{al}^{11}$. Young stroke (age $<50$ years) comprised of $13.7 \%$ of all patients which closely correlated with study done by Sallam et al $(13.6 \%)^{14}$ and Gauri et al $(19 \%)^{15}$. Among stroke patients males $138(63 \%)$ were predominent than females $81(37 \%)$. Male female ration was 1.7:1. Stroke is male predominant disease shown in different studies in Bangladesh ${ }^{16-18}$. They found M:F ratio 2.75:1, 2.53:1 and 3.44:1 respectively. This study also shows both ischemic \& hemorrhagic strokes are male predominant [Ischemic-male $120(86.77 \%)$, female $70(32 \%)$; hemorrhagic-male $18(8.2 \%)$ and female $11(5 \%)]$, which also correlated with another study done abroad ${ }^{9}$. In this study out of 219 patients, $120(54.8 \%)$ were either current smoker or ex-smoker and 99(45.2\%) were nonsmoker. In another two studies done in this country showed $39.5 \%$ and $44 \%$ stroke patients were smoker respectively ${ }^{16,19}$. Regarding hemiplegia/ monoplegia 78(35.61\%) patients had weakness in both sides of the body, 66(30.13\%) patients had weakness on his left side and $36(16.4 \%)$ had weakness in right side of the body. This observation closely correlates with the study done in India by Chitrambalam et al (hemipegia <45years 93.3\%, in $>45$ years 89.2$)^{20}$.

In this study common risk factors correlated with the study done both in home and abroad. Dyslipidaemia was present in 185(84.5\%) patients, HTN in 165(75.3\%), smoking habit in $120(54.8 \%)$, DM in 105(47.95\%) and IHD in $42(19.2 \%)$ patients respectively. H/O recurrent stroke was found in $52(25.1 .25 \%)$ cases. This observation correlates with the study of Sarker, 2015 (found dyslipidemia in $53.75 \%$, HTN in $60 \%$, DM in $27.5 \%$, IHD in $11.3 \%$ and recurrent stroke in $20 \%$ cases $)^{18}$ and HTN in $58.6 \%$, DM in $32.1 \%$, in khan; $2000^{16}$ and $\mathrm{HTN}$ series in $65 \%$ and DM in $21 \%$ ullah et al $1993^{19}$ series. This study shows $190(87.79 \%)$ patients had Ischemic stroke and $29(12.3 \%)$ had hemorrhagic stroke. This data correlated with studies done in home and abroad. In studies done by Aiyar et $\mathrm{al}^{21}$ shows infraction in $70 \%$ and hemorrhage in $26 \%$ cases. Eapen et $\mathrm{al}^{5}$ showed infraction in $68 \%$ and hemorrhage in $32 \%$ cases. Regarding clinical presentation 180(82.19\%) patients had hemiplegia, 62(28.3\%) patients had speech involvement and 31(14.15\%) cases had altered sensorium which also correlates with the studies in home $\&$ abroad $^{9,16,19}$.

\section{Conclusion:}

In this study it was found that ischemic stroke $(87.7 \%)$ was more common than hemorrhagic stroke $(12.3 \%)$. Most of the patients $(42.5 \%)$ were in between 61-70 years of age. Dyslipidemia was most frequent among risk factors (84.5\%), followed by $\operatorname{HTN}(75.3 \%)$, smoking habit (54.8\%), DM (47.9\%). H/O recurrent stroke (25\%), IHD (19.2\%). Most common clinical presentation was hemiplegia/ monoplegia followed by speech involvement. 


\section{References:}

1. Hartona S. Expriences from a multicenter stroke register: a preliminary report. Bull WHO 1976;54(5): 541-53.

2. Bath P. Acute stroke. In: Machin D, Day S, Green S, eds. Textbook of clinical Trials. $2^{\text {nd }}$ ed. Hoboken: Wiley; 2006:179-80

3. Das S K, Banerjee TK, Biswas A, Raut D K, Mukherjee C S, Chaudhuri A, et al. A prospective community based study of stroke in Kolkata, India, Stroke. 2007; 38(3):906-10.

4. Nagaraja D, Gururaj G, Girish N, Panda S, Roy A K, Sarma G R K et al. Feasibility study of stroke surveillance: data from Bangalore, India. Indian J Med Res 2009; 130:396-403.

5. Eapen R P, Parikh J H, Patel N T. A Study of clinical profile and risk factors of cerebrovascular stroke., Gug Med J. 2009;64(2):47-54.

6. Kameshwar P, Kapil S. Stroke in young: An Indian perspective. Neurol India. 2010; 58(3):343-50.

7. Feigin V, Lawes C, Bennet D, Barker C S, Parag V. Worldwide stroke incidence and early case fatality in 56 population based studies: a systematic review. Lancet Neurol 2009;8(4):355-69.

8. Bangladesh Baureu of statistics. Year Book2016. Page-12.

9. Chirayu V, Vaidya, Drusty K, Majmudar. A restrospective study of clinical profile of stroke patients from GMERS Medical college and Hospital, Gandhinagar, Gujrat, International Journal Clin Trials 2014; 1(2):62-66.

10. Shah B, Mather P. Workshop report on stroke surveillance in India. In: Shah B, Mather $P$, eds. WHO report. New Delhi: Division of noncommunicable Diseases, Indian council of Medical Research; 2006:1-33.

11. Maskey A, Parajuli M, Kohli S C. A study of risk factors of stroke in patients admitted in manipal teaching hospital, Pokhara, Kathmandu University J, 2011;9(36):244-7.

12. Awad S M, Al-jumaily HF, Al-Dulaimi KM, Adbulghafoor $\mathrm{RH}$. Assessment of major risk factors among stroke patients. Saudi Med J. 2010;31(9):1028-31.

13. Ukoha OB, Ajaegbu O, Eke CO. A Review of stroke cases in a military hospital in Nigeria. AFRIMEDIC J. 2012;3(2):30-33.

14. Salam AR, Aghbari KA. The clinical profile of stroke: a Yemeni experience. I Med J. 2009;43(2):115-21.

15. Gauri LA, Kochar DK, Joshi A, Jain R, Gupta $S$, Saini $G$, et al. A study of risk factors and clinical profile of stroke at Bikaner. JAPI 2000;48(1).

16. Khan MRK. Relationship between blood Lipids, lipoproteins and ischemic stroke (MD-Thesis). Bangabandhu Sheikh Mujib Medical University, Dhaka-2000.

17. Hannan MA. Study of seasonal variation of stroke (Thesis). Sheikh Mujib Medical University, Dhaka-1999.

18. Sarker I. Evaluation of post-stroke dementia in different types of stroke patients(Thesis), Bangladesh College of Physicians and Surgeons, Dhaka; 2015.

19. Ullah AKMA, Habib M, Mohammad QD, Ahmed S, Nahar S. Review of risk factors of stroke: study of 100 cases. Bangladesh Journal of Neuroisciences. 1993;9:11-20.

20. Chitrambalam P, Baskar D, Revathy S. Astudy on stroke in young and elderly in Rajib Gandhi government general hospital, Chennai. International J Clin Med 2012;3:184-9.

21. Aiyar et al. A study of clinical radiological correlation in cerebrovascular- stroke- A study of 50 cases. Guj Med J 1999;52:58-63. 